\title{
NOTE
}

\section{Shell disease: abnormal conchiolin deposit in the abalone Haliotis tuberculata}

\author{
Sylvain Huchette ${ }^{1,2, *}$, Christine Paillard ${ }^{2}$, Jacques Clavier ${ }^{2}$, Robert Day ${ }^{1}$ \\ ${ }^{1}$ Department of Zoology, The University of Melbourne, Parkville 3052, Victoria, Australia \\ ${ }^{2}$ Institut Universitaire Européen de la Mer, URA CNRS 1513, LEMAR, Université de Bretagne Occidentale, BP 809, \\ 29285 Brest Cedex, France
}

\begin{abstract}
Shell disease in the abalone Haliotis tuberculata L. is characterized by a conchiolin deposit on the inner surface of the shell. The gross clinical signs appear similar to the Brown Ring Disease (BRD) of clams. BRD has been extensively described in clams and is known to be responsible for severe mortalities and the collapse of the clam aquaculture industry in western France. In the clam, it was found to be caused by the infection of the mantle by Vibrio tapetis. Brown protein deposits have been observed in various abalone species around the world; some of these have been associated with a fungal infection in New Zealand, but the ones described here are similar to bacterial infections observed in clams. Larger animals appeared to be more affected by the disease, and a positive correlation of the number of successive infections found in the shells with the level of infestation of the shell by borers suggests that boring polychaetes and sponges may be vectors of the disease, or that the parasite infestation may increase the susceptibility of the animal to this infection. There is no evidence, however, that this infection causes mortality in abalone.
\end{abstract}

KEY WORDS: Shell disease $\cdot$ Bacteria $\cdot$ Haliotis tuberculata $\cdot$ Calcification $\cdot$ Shell aging $\cdot$ Conchiolin deposit

Resale or republication not permitted without written consent of the publisher

\section{INTRODUCTION}

Brown Ring Disease (BRD) has been described in various clam species and has caused severe mortality in clam populations in western France (see review by Paillard et al. 1994, Paillard 2004). Oysters affected by Juvenile Oyster Disease (JOD) also exhibit similar pathological signs and this disease may lead to mortality in eastern oysters Crassostrea virginica (Bricelj et al. 1992, Paillard et al. 1996, Ford \& Borrero 2001). In some cases, JOD also induces abnormal conchiolin deposits on the inner shell. Research on BRD has led to the isolation and identification of a pathogenic agent, Vibrio tapetis (Paillard \& Maes 1990), and signs of disease were reproduced by bacterial challenge in laboratory experimental infection (Paillard \& Maes 1995a,b). In the clam, the bacterium adheres to and colonises the periostracum lamina, thereby affecting mantle secre- tion which results in anomalous deposition of brown conchiolin in the inner shell.

Brown protein depositions have been described in the shells of Haliotis rubra (Marshall \& Day 2001), $H$. laevigata (Shepherd \& Triantafillos 1997) and $H$. scalaris (Shepherd \& Huchette 1997) and observed in other species such as $H$. kamkatchana, $H$. corrugata and $H$. fulgens (S. Shepherd, SARDI, South Australia, pers. comm.), but thus far have not been associated with a specific pathogen. In those studies, the depositions were associated with shell consolidation after infestation by boring parasites. Extra layers of nacre were deposited after each protein deposit, thickening the shell in the spire area (Marshall \& Day 2001).

In the present study, we describe the pathological signs of the conchiolin deposit observed in a population of abalone Haliotis tuberculata L. from Morlaix, France, and we evaluate the prevalence of the disease in relation to shell size (age) and infestation by parasites. 

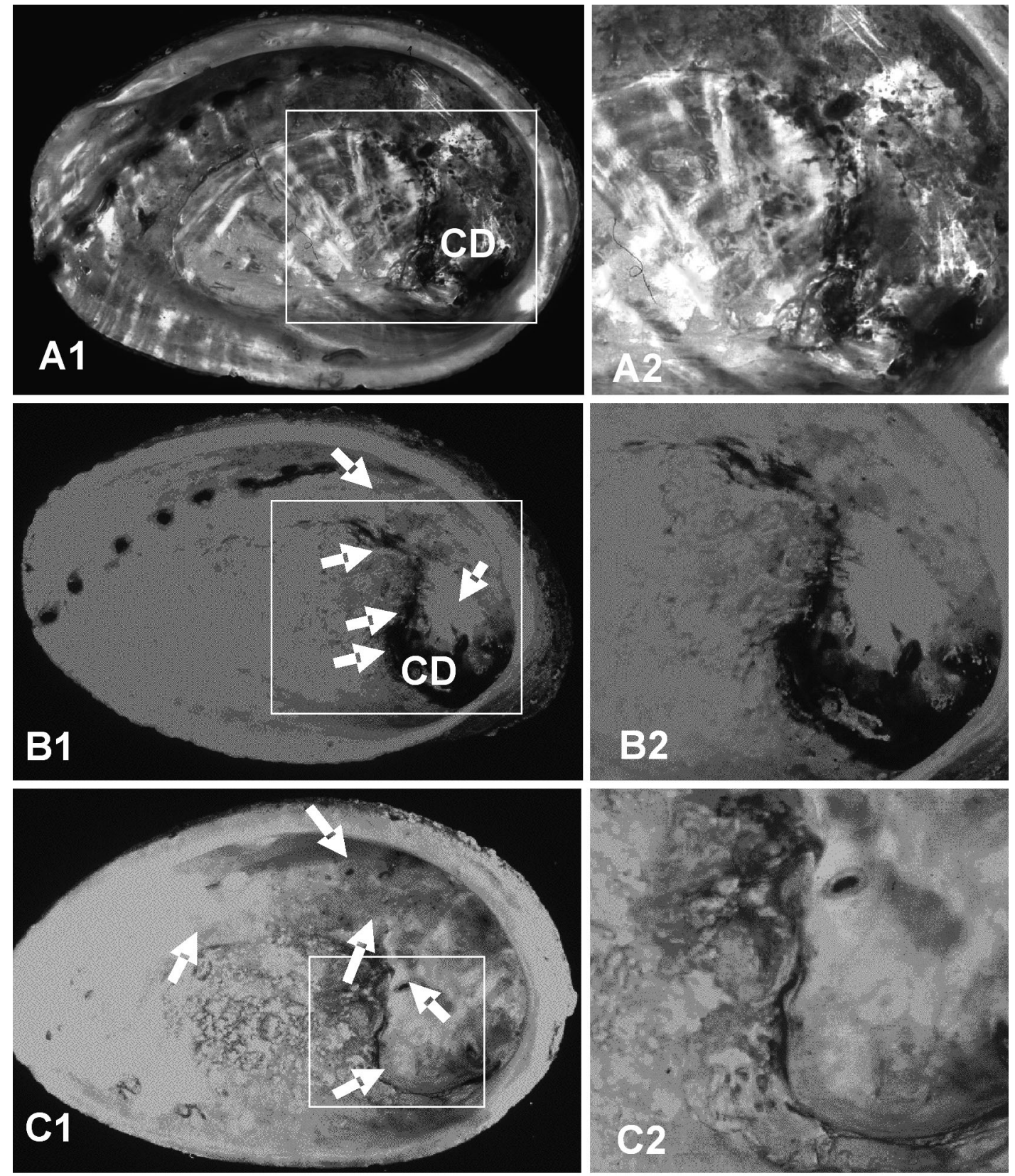

Fig. 1. Haliotis tuberculata. (A1,2) A fresh conchiolin deposit (CD) in the shell; $(\mathrm{B} 1,2)$ partly calcified conchiolin deposition; and $(\mathrm{C} 1,2)$ fully calcified conchiolin deposition. Backlight in photo $(\mathrm{C} 1,2)$ also shows high level of parasite infestations of the specimen. Shells shown in (A) and (B) were classified as category 2 and those shown in (C) as category 3. Arrows show where re-calcification occurred to cover the $\mathrm{CD}$

\section{MATERIALS AND METHODS}

A sample of 62 adult abalone was collected on May 6, 2002, by SCUBA divers in the port of Primel $\left(48^{\circ} 40^{\prime} \mathrm{N}, 3^{\circ} 55^{\prime} \mathrm{W}\right)$, Finistère Nord, West Brittany, France.

When present, conchiolin deposits were found to cover a large area of the inner shell. The shells could be classified in 4 different categories: (0) healthy shell, (1) minor calcification abnormalities without conchiolin deposition, (2) brown protein spots, freshly deposited conchiolin deposit without calcification or partly calcified conchiolin deposit, and (3) totally calcified conchiolin deposits. The size and sex of each animal were recorded. The shells were measured with vernier calipers to the nearest $0.5 \mathrm{~mm}$. 
As in Shepherd \& Huchette (1997), the shell spires were ground using an electric grinder until a tiny hole became visible; they were then polished using fine sandpaper. A drop of hydrochloric acid was used to dissolve the laminar nacre preferentially. The number of conchiolin deposits was then counted under a stereomicroscope.

The level of infestation by commensals in the shells was evaluated by looking through the shell using a bright light. Two types of commensals were recorded: the number of burrows from polychaetes Polydora spp. and the frequency of holes left by the sponge Cliona sp. as described by Clavier (1989). These commensals can become parasites when their perforations reach the live tissues of the animals. Shells were divided into 4 areas: shell edge, muscle attachment area, old respiratory pores and spire. One $\mathrm{cm}^{2}$ of each area was scored according to the following scale: $0=$ no traces of parasite; 1 = light infestation, i.e. 2 to 5 Cliona holes; $2=6$ to 10 Cliona holes; $3=11$ to 20 Cliona holes or 1 polychaete burrow; 4 = heavy infestation, i.e. over 20 Cliona holes and several polychaete burrows; $5=$ extreme infestation, sponge-like shell (Fig. 1C). Thus, the score for each individual may range from 0 to over 20 . Polychaete burrows were wider and deeper than Cliona sp. holes and were generally found in shells already infested by Cliona sp. Because conchiolin deposit prevalence increased with the size of the animal, a partial correlation was carried out between the number of conchiolin deposits, the abalone age and the parasite infestation levels, correcting these variables for maximum shell length (Quinn \& Keough 2002).

\section{RESULTS}

Infected abalone are shown in Fig. 1. Fifty-nine percent of the shells were found with at least 1 conchiolin deposit (Fig. 2). Up to 5 conchiolin deposits were found in 1 shell. Only 2 shells were found with freshly deposited conchiolin deposits. All other shells with conchiolin deposits had a calcified layer deposited on the top of the brown protein layer, as described by Marshall \& Day (2001). Conchiolin deposit incidence increased rapidly in a shell length of over $85 \mathrm{~mm}$ and reached over $90 \%$ in the 110 to $120 \mathrm{~mm}$ size class (Fig. 3).

The multiple regression between the number of conchiolin deposits, maximum shell size, the age and shell infestation levels was significant $\left(F_{1,60}=53.4, \mathrm{p}<\right.$ 0.001): number of conchiolin deposits $=0.24 \times$ infestation level +0.46 . Infestation of the shell by parasite was the only significant variable. The number of conchiolin deposits increased significantly with infestation level (Fig. 4).

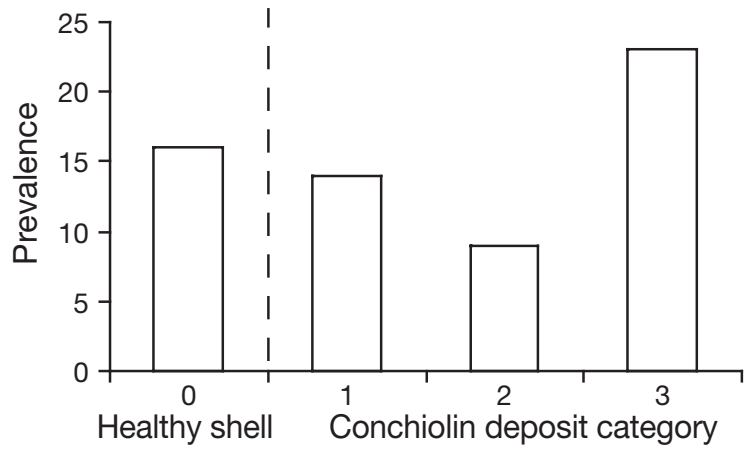

Fig. 2. Haliotis tuberculata. Prevalence of conchiolin deposit categories in the sample $(\mathrm{N}=62) .0=$ healthy shell, $1=$ minor calcification abnormalities without conchiolin deposition, 2 = brown protein spots, freshly deposited conchiolin deposit without calcification or partly calcified conchiolin deposit, $3=$ totally calcified conchiolin deposits

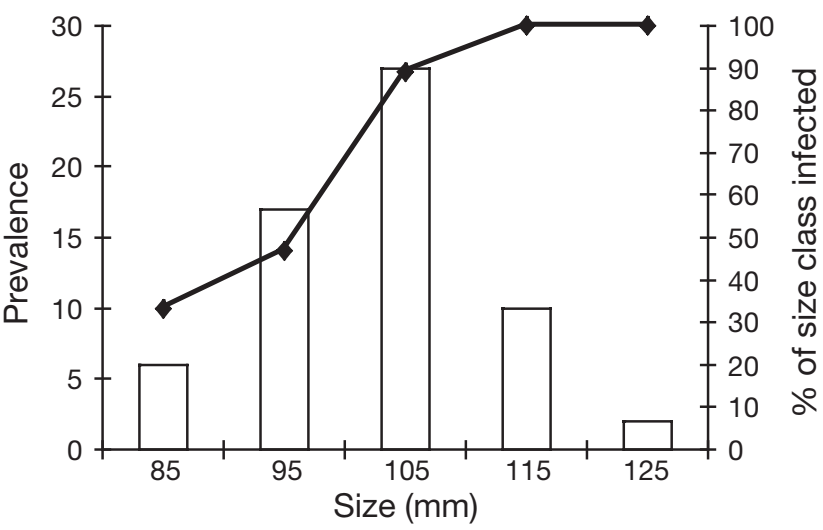

Fig. 3. Haliotis tuberculata. Size frequency distribution of our animal sample (bars, $\mathrm{N}=62$ ) and prevalence of conchiolin deposit in the spire (line) versus maximum shell length (the middle of each size class is displayed on the $x$-axis)

\section{DISCUSSION}

Brown deposits and shell lesions were described for 3 abalone species from New Zealand (Grindley et al. 1998). These deposits were located only under the shell spire, occurred as blisters of conchiolin and resulted from a localized fungal infection of the shell. The brown depositions in the shells described here formed a thin layer of conchiolin that entirely covered the inside of the shell with the exception of the muscle attachment area. The frequency of brown depositions in the shells of Haliotis tuberculata showed similar patterns to those found for $H$. scalaris (Shepherd \& Huchette 1997), $H$. rubra (Marshall \& Day 2001) and H. laevigata (Shepherd \& Triantafillos 1997) in Australia. The brown depositions found in the first 3 species are darker, more pronounced and more frequent than in H. laevigata. In- 


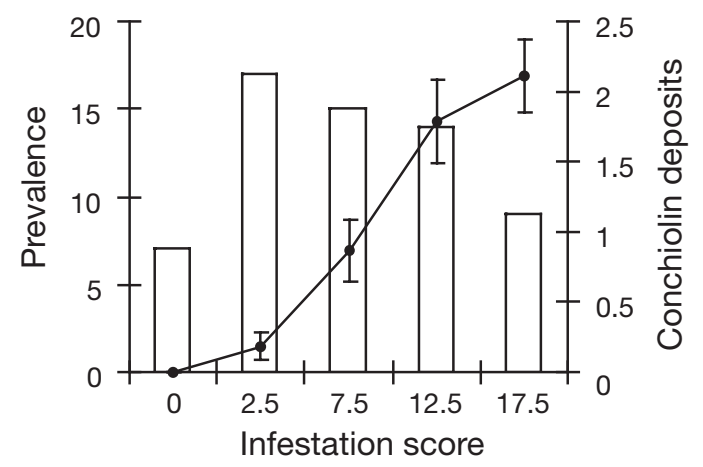

Fig. 4. Haliotis tuberculata. Frequency distribution of infestation scores in the animal sample (bars, $\mathrm{n}=62$ ) and average number of conchiolin deposits for each category (line). For details see 'Materials and methods'. The middle of each score class is displayed on the $x$-axis. Error bars show mean $\pm \mathrm{SE}$

terestingly, the first 3 species have a similar shell morphology (corrugated shell with prominent respiratory pores) and similar habitat and behaviour (juveniles and a large proportion of adults hide in crevices or under rocks during the daytime). McDiarmid et al. 2004) found that $H$. rubra is more susceptible to parasite infestation than $H$. laevigata, which has a smoother shell. Thomas \& Day (1995) reported that $H$. rubra deposited a thick brown protein patch in response both to holes drilled in the shell by a predatory mollusc and to holes which were experimentally drilled in the shell. Penetration of the shell by parasites was always also associated with the deposition of dark protein. These protein depositions are probably dense protein matrix produced by the animal to repair its shell. In all cases, however, the depositions remained localized around the hole or the burrow of the parasite. In all species observed, the conchiolin deposits tended to extend over a large area inside the shell.

Marshall \& Day (2001) suggested that the deposition of the dark protein layer may help in the consolidation of shell infested with polychaetes and found that thicker layers of nacre were deposited in infested shells. Thus, the protein-rich layer may also help in the calcification of the shell. Parasite infestation may increase the susceptibility of the shell to bacterial infection when the parasite burrows penetrate to the inside of the shell, or parasites such as polychaete may be the vector of this infection. Other studies on bivalves-e.g. ligament erosion in oyster (Dungan \& Elston 1988), BRD in clam (Paillard \& Maes 1995a) suggest that bacteria colonization of periostracum and ligament can cause deposition of brown protein (see review by Paillard et al. 2004).

Mortalities of abalone have been associated with Vibrio infections in China (Vibrio fluvialis II, Li et al. 1998, 1999) and more recently in France (Vibrio sp.,
Nicolas et al. 2002). These mortalities occurred in the summer when water temperatures were high. Experimental infection conducted by IFREMER and mortalities induced by the Syndicat Mixte pour l'équipement du Littoral (SMEL) in Manche suggest that the pathogenic agent was probably Vibrio carchariae and found that mortalities were associated with elevated water temperature (Nicolas et al. 2002, Huchette \& Clavier 2004). Shell abnormalities (whether due to bacterial infection or not) may weaken abalone or cause mortalities of weaker abalone that fail to fight the infection. The fact that several conchiolin deposits could be observed in the same shell shows that this disease is not necessarily fatal to the animal, that it is probably the result of a pathogen less virulent than $V$. carchariae and that the deposition of a brown layer does not prevent subsequent infections. On several occasions, it was observed that conchiolin deposits do not prevent further perforation of the shell by polychaetes in the spire. Parasite worms may also be the carrier and vector of the infection as in the coral bleaching disease described by Sussman et al. (2003). Recent investigations found that this chronic infection was also present in other populations of the Bay of Brest, where it appears to have a high prevalence and may significantly affect the dynamics of abalone populations in western France.

Acknowledgements. S.H. was the recipient of a Postgraduate Overseas Research and Experience Scholarship from the University of Melbourne. The exchange program between the laboratories was supported by the French Embassy in Australia. Thanks go to S. Gausson, A. Le Mercier and G. Choquet for technical assistance.

\section{LITERATURE CITED}

Bricelj VM, Ford SE, Borrero FJ, Perkins FO, Rivara G, Hillman RE, Elston RA, Chang J (1992) Unexplained mortalities of hatchery-reared, juvenile oysters, Crassostrea virginica (Gmelin). J Shellfish Res 11:331-347

Clavier J (1989) Infestation of Haliotis tuberculata shells by Cliona celata and Polydora species. In: Guzman del Proo SA, Tegner MJ, Shepherd SA (eds) Abalone of the world. Biology, fisheries and culture supplementary papers, La Paz, p 16-20

Dungan CF, Elston RA (1988) Histopathological and ultrastructural characteristics of bacterial destruction of hinge ligaments of cultured juvenile Pacific oysters, Crassostrea gigas. Aquaculture 72:1-14

Ford SE, Borrero FJ (2001) Epizootiology and pathology of Juvenile Oyster Disease in the eastern oyster, Crassostrea virginica. J Invertebr Pathol 78:141-154

Grindley RM, Keogh JA, Friedman CS (1998) Shell lesions in New Zealand Haliotis spp. (Mollusca, Gastropoda). J Shellfish Res 17:805-811

Huchette SMH, Clavier J (2004) Status of the ormer (Haliotis tuberculata L.) industry in Europe. J Shellfish Res 23:951-956 
Li T, Ding M, Zhang J, Xiang J, Liu R (1998) Studies on the pustule disease of abalone (Haliotis discus hannai Ino) on the Dalian coast. J Shellfish Res 17:707-711

Li T, Xiang J, Liu R, Ding M, Shi P, Wang S (1999) Studies on bacteriophage of pustule disease of abalone Haliotis discus hannai. Oceanol Limnol Sin 30:374-380 (in Chinese with English Abstract)

Marshall DJ, Day R (2001) Change in the rate of shell deposition and shell microstructure in response to shell borers in the abalone Haliotis rubra. Mar Freshw Behav Physiol 34: 189-195

McDiarmid H, Day EG, Wilson R (2004) The ecology of polychaete that bore in abalone shells in Victoria. J Shellfish Res 23:1179-1188

Nicolas JL, Basuyaux O, Mazurie J, Thebault A (2002) Vibrio carchariae, a pathogen of the abalone Haliotis tuberculata. Dis Aquat Org 50:35-43

Paillard C (2004) A short review of brown ring disease, a vibriosis affecting clams Ruditapes philipinarum and Ruditapes decussatus. Aquat Living Resour 17:467-475

Paillard C, Maes P (1990) Étiologie de la maladie de l'anneau brun chez Tapes philippinarum: pathogenicité d'un Vibrio sp. C R Acad Sci Ser III 310:15-20

Paillard C, Maes P (1995a) The Brown Ring Disease in the Manila clam, Ruditapes philippinarum. I. Ultrastructural alterations of the periostracal lamina. J Invertebr Pathol 65:91-100

Paillard C, Maes P (1995b) The Brown Ring Disease in the

Editorial responsibility: Albert Sparks,

Seattle, Washington, USA
Manila clam, Ruditapes philippinarum. II. Microscopic study of the brown ring syndrome. J Invertebr Pathol 65: 101-110

Paillard C, Maes P, Oubella R (1994) Brown ring disease in clams. Annu Rev Fish Dis 4:219-240

Paillard C, Ashton-Alcox K, Ford SE (1996) Changes in bacterial densities and hemocyte parameters in eastern oysters, Crassostrea virginica, affected by juvenile oyster disease. Aquat Living Resour 9:145-158

Paillard C, Leroux F, Borrego JJ (2004) Bacterial disease in marine bivalves: review of recent studies. Trends and evolution. Aquat Living Resour 17:477-498

Quinn RL, Keough MJ (2002) Experimental design and data analysis for biologists. Cambridge University, Cambridge

Shepherd SA, Huchette S (1997) Studies on southern Australian abalone (genus Haliotis). XVIII. Ring formation in H. scalaris. Molluscan Res 18:247-252

Shepherd SA, Triantafillos L (1997) Studies on southern Australian abalone (genus Haliotis). XVII. A chronology of $H$. laevigata. Molluscan Res 18:233-246

Sussman M, Loya Y, Fine M, Rosenberg E (2003) The marine fireworm Hermodice carunculata is a winter reservoir and spring-summer vector for the coral-bleaching pathogen Vibrio shiloi. Environ Microbiol 5:250-255

Thomas M, Day RW (1995) Site selection by a small drilling predator - why does the gastropod Haustrum baileyanum drill over muscle tissue of the abalone Haliotis rubra? Mar Freshw Res 46:647-655

Submitted: July 30, 2003; Accepted: June 4, 2005

Proofs received from author(s): February 10, 2006 